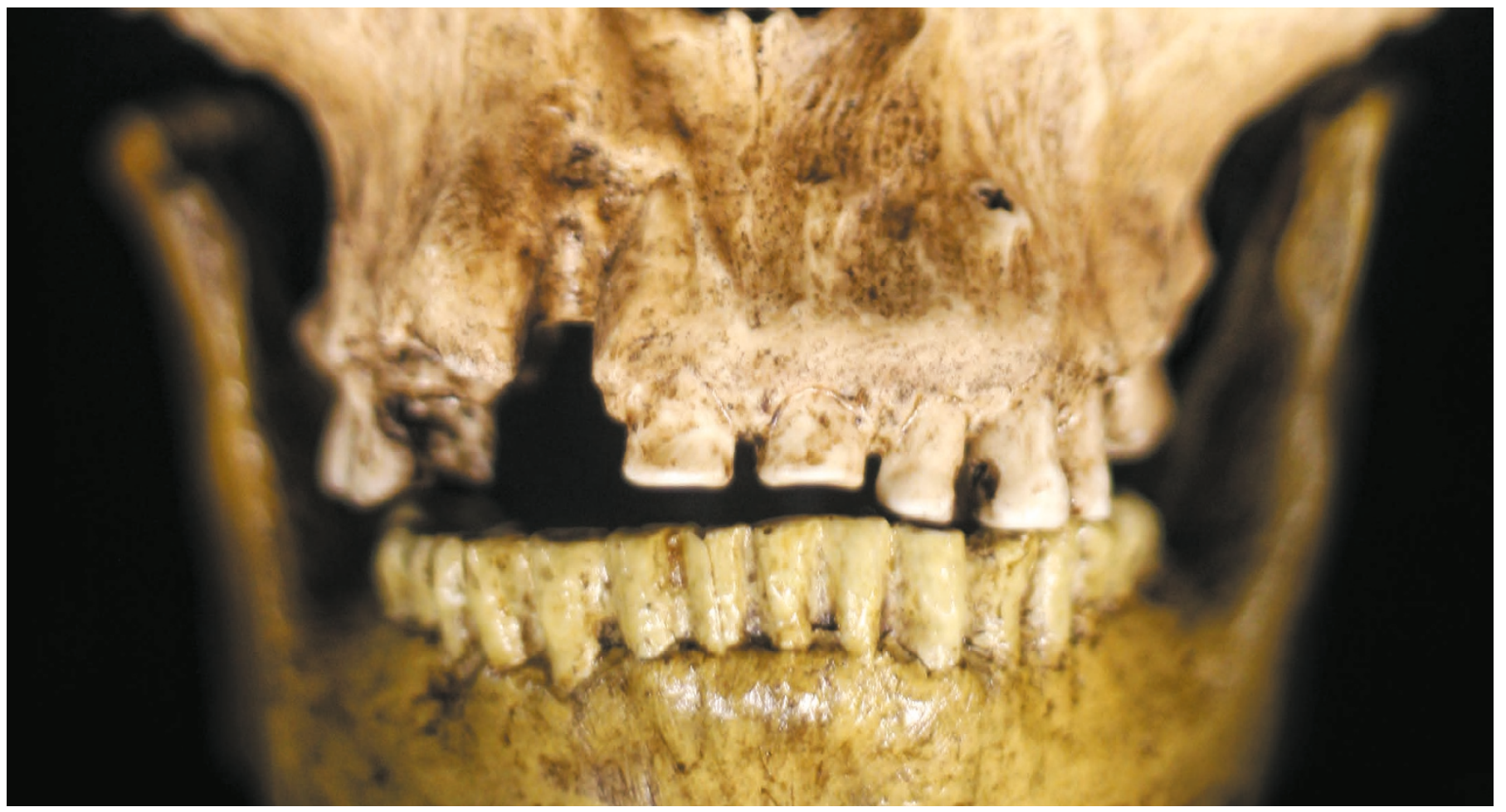

Cast of a reconstructed Neanderthal skull. The teeth of fossil hominins can reveal what our extinct relations were able to eat.

\title{
PALAEONTOLOGY
}

\section{Evolution with teeth}

\section{Louise Humphrey applauds a treatise on the dental roots of the human story.}

$\mathrm{T}$ eeth are a unique, enduring archive of a lifetime's experiences, stretching back to before birth. They can reveal childhood hardship, seasonal migration, exposure to pollution, radiation or congenital syphilis, cultural modification, and age at death - as well as a wealth of information about diet. Thus, the teeth of our hominin predecessors in the archaeological and fossil record are a prodigious store of evidence. It's hardly surprising that many scientists dedicate their careers to unlocking the evidence from modern and fossil teeth.

In Evolution's Bite, palaeoanthropologist Peter Ungar offers a compelling account of how the interaction of teeth, diet and environment has shaped human evolution. This tale ranges from the formidable dentition of early hominin Paranthropus boisei, which roamed eastern Africa between 2.3 million and 1.3 million years ago, to the mismatched jaws and teeth of many living humans. The book also takes us on a fascinating tour of the fossil and archaeological record, climate history, field observations and lab-based analysis.

To kick off his exploration of human evolution, Ungar analyses the interplay of food and tooth form. Hard, brittle foods such as seeds can be crushed between teeth with rounded cusps and shallow basins. Tough foods, such as raw meat or leaves, need to be sliced or sheared by teeth with thinner, blade-like crests. But when researchers set out to learn whether living primates' diets could be predicted from the shape of their teeth, study after study revealed a mismatch between observed and expected diet. Tooth

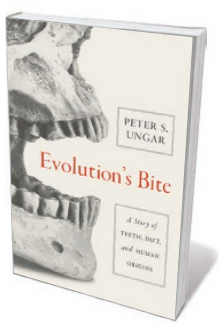

Evolution's Bite: A Story of Teeth, Diet, and Human Origins

PETER S. UNGAR

Princeton University Press: 2017. cheek bones to accommodate massive chewing muscles, anchored by a skull-top crest. Scientists assumed that these were adaptations for crushing nuts and roots, which would leave pits and craters on the teeth. But microwear analysis revealed just a few wispy scratches, confirming a mismatch between capability and choice. Ungar concludes that teeth and jaws have evolved to contend with less-accessible foods that animals resort to when their preferred diet is unavailable.

Palaeoanthropologists and archaeologists continue to debate what it means to be human (S. C. Antón et al. Science 345, 1236828; 2014); Ungar demonstrates how changes in food choice, acquisition and processing intersect with many perspectives on this issue. Humans' large brains - five times the mass expected in a similarly sized mammal demand a reliable source of high-quality food. Our linear body allows us to access diverse sources of nourishment by hunting down prey through endurance running. Sharing food within the immediate family or broader community underpins our social interactions and helps to ensure that our children survive. Technological advances such as tool use and cooking enable us to extract otherwise inaccessible nutrients and energy. 
Ungar suggests that the concentrations of stone artefacts and butchered animal remains found at sites such as Koobi Fora in Kenya, and dated to around 2 million years ago, mark the point at which meat and bone marrow became a regular part of the human diet. $\mathrm{He}$ shows how teeth from early specimens of the genus Homo are better adapted for slicing than those of their australopith predecessors, and varied microwear suggests that Homo had more flexible diets. Tool use and, later, cooking may have relieved selective pressure for large teeth and jaws, but the reduction in tooth size seems to have been gradual.

A more varied diet, aided by increasingly sophisticated technologies, enabled huntergatherers to colonize most of the world's icefree land masses by the end of the last ice age, around 12,000 years ago. The transition from foraging to agriculture - the Neolithic Revolution - had profound implications, which Ungar describes as the point at which we "change the rules of the game and begin to stock the buffet ourselves". Permanent settlement and a predictable larder allowed larger communities to form complex societies. In some places, environmental change almost certainly forced the transition: at Abu Hureyra in Syria, the first tentative signs of plant cultivation around 13,000 years ago coincide with the start of the cold, arid Younger Dryas, when wild foods became scarcer.

For enthusiasts of the 'palaeo' diet, this is when it all went wrong. But as Ungar shows, versatility is key to the human dietary niche. It would be pointless to try to emulate a single ancestral diet: there wasn't one. Humans have continued to evolve since the Neolithic Revolution, and many of us have enzymes that our ancestors did not have, enabling us to digest starchy foods effectively and digest milk as adults. It can be argued, however, that our teeth and jaws are out of sync with modern menus. Many people today have crowded, crooked or impacted teeth because our jaws are underdeveloped - a soft, processed diet just doesn't stimulate sufficient growth (see Daniel Lieberman's The Evolution of the Human Head; Harvard Univ. Press, 2011). The human love affair with sugary foods also leads to tooth decay and gum disease caused by bacteria that feast on residues on our teeth.

Homo sapiens is the last of the hominin lineage. But as evidence accumulates that diverse hominin species coexisted from at least 3.5 million years ago until around 40,000 years ago, a future challenge will be to understand how different foraging strategies enabled them to share the landscape.

Louise Humphrey is a researcher in human origins at the Natural History Museum in London.

e-mail:l.humphrey@nhm.ac.uk

\section{Books in brief}

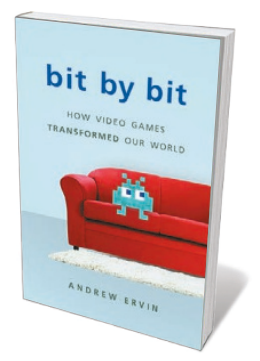

Bit by Bit: How Video Games Transformed Our World

Andrew Ervin BASIC (2017)

Whether sparked by Pong in the 1970s or Minecraft in the 2010s, humanity's love affair with video games is enduring; US consumers alone spent US $\$ 23.5$ billion on them in 2015. Andrew Ervin slaloms through their cultural and technological history, from physicist William Higinbotham's 1958 analog simulation Tennis for Two to Atari classics, arcade stalwart Pac-Man and the Warcraft franchise. Ervin even plays the original games, research that involves the installation of vintage computer drives and an "obscenely loud" Donkey Kong machine. A vivid foray into alternative worlds.

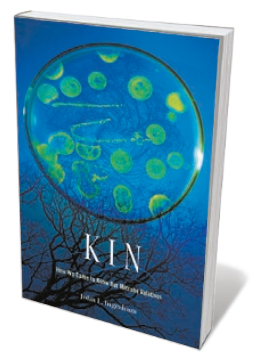

Kin: How We Came to Know Our Microbe Relatives

John L. Ingraham HARVARD UNIVERSITY PRESS (2017)

Charles Darwin knew microbes as "infusoria", and left them off his partial tree of life - little dreaming of how they dominate it, or of their intimate relationship with humanity. That kinship, reveals microbiologist John Ingraham in this succinct scientific chronicle, began to emerge in the 1960s and 1970s with revolutionary findings such as Carl Woese's discovery of archaea. Ingraham deftly traces the rise of relevant fields, and highlights landmark research on the gut microbiome, the putative origins of life in oceanic hydrothermal vents and more.

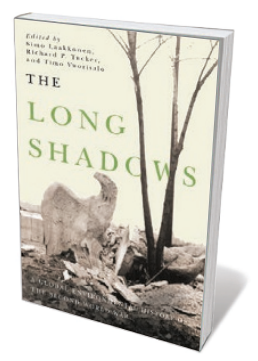

\section{The Long Shadows}

Eds Simo Laakkonen, Richard P. Tucker and Timo Vuorisalo OREGON STATE UNIVERSITY PRESS (2017)

The tens of millions who died in the Second World War were not its sole casualties. Unprecedented militarization of land, sea and air by war industries and powerful new arms devastated ecosystems around the world. Simo Laakkonen, Richard Tucker and Timo Vuorisalo helm a revelatory collection of essays on the conflict's "long shadows", from toxic-waste dumping in the Soviet Union to Nazi environmental policy and the "lunar" landscapes of what is now Guyana, a brutal legacy of bauxite mining triggered by the aluminium boom.

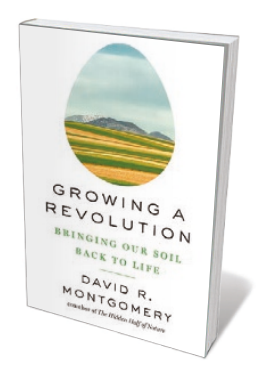

Growing a Revolution: Bringing Our Soil Back to Life

David R. Montgomery W. W. NORTON (2017)

How can humanity feed its burgeoning billions when one-third of agricultural soil is degraded? Pondering that question propelled geologist David Montgomery on a three-decade, six-continent survey of farmland. The insights gleaned add nuance to his pointed critiques of agrotechnology and organic farming, but it's the findings on rapid soil restoration that compel. Montgomery shows how precision fertilization, no-till regimes and complex crop rotation benefit soil ecology and nutrient cycling - and bring biology back into the soil-fertility picture along with physics and chemistry.

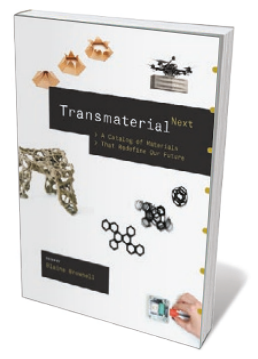

Transmaterial Next

Blaine Brownell PRINCETON ARCHITECTURAL PRESS (2017)

Sustainable materials must satisfy multiple cross-cutting criteria, from low or no environmental impact to design applicability and high performance. Those that made the cut in architect Blaine Brownell's eye-popping catalogue possess that magical mix of green credibility and sleek aesthetic: BlingCrete (light-reflecting concrete), pollution-filtering bricks, energy-harvesting walls, foamed-wood insulation, touch-responsive surfaces. A foretaste of how near-future science could transform engineering and design. Barbara Kiser 